\title{
AS CIRCUNSTÂNCIAS DO PROCESSO DE RECONFIGURAÇÃO DA ESCOLA PROFISSIONAL DE ASSISTÊNCIA A PSICOPATAS DO DISTRITO FEDERAL
}

The Circumstances of the Reconfiguration Process of the Professional School of Assistance to Psychopaths of the Federal District

Las Circunstancias del Proceso de Reconfiguración de la Escuela Profesional de Ayuda a Psicópatas del Districto Federal

WellingtonMendonçadeAmrim

ledadeAlencar Barreira

\section{Resumo}

Estudb históico-social baseadb emanálise dba mental. Trata das ciranstâncias do processo derecorfiguração da EscolaProfissional deEfermeriros eEfermeriras do SenviçodeAssistêndaa Psicopatas doDistritoFederal, na primerira medadedb séalo XX futura EscoladeE fermagemAlfredo Pinto, da L hiversidadeFederal do Estadodo Rio dejaneiro. Objeivos: Descrever os novimentos queasaúdepúdicaeapsiquiatiadesenvolveram noânbito dorecémarganizadoMristério daEducaçãoe SaúdePública, para seadequaremàs políticas do iníciodo período Vargas; eanalisar as características daEscola Profissional deE rfermeiros eE rfermeiras edaEscolaAmaNkeryquecorrespondamavisões distintas. Os campos dasaúdepúdica, da psiquidriae daenfermagemseestruturarama partir dos prinápios devisão edvisão, quecrientaramas lutas, as controvérsias eas competiçães entre os diversos agentes envolvidos eimpuse ramos limites eas possibilidades histónicas nestas duas escolas deerfermagem no Distrito Federal.

Palauras-dhave Effermagem HstóniadaEfermagem Escolas deEfermagem

\begin{abstract}
Resumen

Historical-sodal study based indoa mentaryanalysis. It Estudiohistórico-sodial besadbenanálisis dba mental. Se dedswiththediranstances of theprocess of recorrigurdion ocpadelas dira nstancias del proceso derecorfiguración of the Professional School of Nurses of the Senvice of delaEsaulaProfesional deEfermeros yEnfermeras dal Assistanceto Psychopaths of theFederal District, inthefirst Senvicio deAy daa Psicópetas del Districto Federal, enla half of CenturyXX futureAffredo Pinto School of Nursing, prineramitaddd sigoXXfuturaEsardadeE termeríaAfredb fromtheFederal University of theState of Rio deJaneiro. Pinto, dela UhiversidadFederd dal Estadb deRiodejaneiro. Objetives: Todescribethemeverents that thepublichedth Objetivos: Describir los movimietosquelasaludpúblicayla andpsychiatryhad developed, in thescope of thenewhy- psiquiatría habían desarrollado, en el ámbito reciénorgarized Mristry of theEducationand Public Health to organizadb del MristeriodeEducacónySaludPública, para adjust itself to the politics of the begining of the Varges ajustarseala politicadel iniciodel periodb Varges; yandizar period and toandyzethedharateristics of theProfessiond lascaracterísticas dela EsardaProfesiond deE Efermerosy School of Nurses and of the Ama Nery School that EffermerasydelaEsadaAmaNkryloquecomespondia a corresponded thedistind visions. Thefields of thepublic visiones distintas. Los campos de la salud pública, de la health, psychiatry and the nursing had struturalized psiquidríaydela enfermeriafueronestruturados a partir thenselvesfrom thepriniples of visionandd dision, wich delosprinapios devisiónydivión quearientarónlas/udres, had gidedthefights, thecortroversies and the compeitions las controversias y las competiciones entre los diversos betheenthediverseinvolvedagents andhadimposed the agentes implicados y habín impuesto los límites y las limits and thehistorica possibilities inthesetwoschools of posiblidades históricas enestes dos esardas deerfermeria, nursing intheFederd District enel Districo Federal.
\end{abstract}

Keymords Nersing NersingHstory. Schools of Nersing

Palabas dave Enfermería Hstoria delaEnfermería. EsarlasdeErermería 
INTRODUÇÃO

Este estudo temcomo dojeto as ciranstâncias do processo de reconfiguração da Escola Profissional de Enfermeiros e Enfermeras do Senviço de Assistênda a Psicopatas do Distrito Federal, na primeira medade do século XX atual Escola de ErfermagemAlfredo Pinto, da Universidade Federal do Estado do Rio de Janeiro. Nb contexto da constituição dos campos da psiquiatria e da saúde púdica

Para operadionalizar a pesquisa, definimos os seguintes objeivos: descrever os movimentos que a saúde pública e a psiquiatria desenvolveram no âmbito do recémorganizado Mnistério da Educação e Saúde Pública, para se adequaremàs políticas do início do período Vargas; e analisar as características da Escola Profissional de Enfermeiros e Enfermeiras (EPEE) e as da Escola Anna Nery (EAN) que correspondiama visões distintas.

METODOLOGIA

Pesquisa de natureza histónico-sodal, baseada em análise doa mental, segundo o entendimento de que umtexto é sempre portador de umdiscurso, não podendo ser visto cono algo neutro e transparente $O$ estudo se apóia no pensamento social de Pierre Bourdieu Evitamos as formas nígidas de análise e prionizanos a busca dos nexos entre as idéas contidas nos disarsos, relacionando texto e contexto.

As fontes prinárias foramos escritos oficiais, cono ofícios, relatónios e outros doa mentos oriundos das dversas instândias do Mristéio da Educação e Saúde Pública; e a legislação de interesse do campo da educação e saúde e artigos dos porta-vozes dos campos da saúde pública, da psiquiatria e da enfermagem Tais fontes foram localizadas nos seguintes acervos: Casa de Osualdo Cruz, da Fiocnz; Arquivo Setorial da Escola de EnfermagemAlfredo Pinto/Laboratório de Pesquisa de História da Effermagem(Laphe) - UNRO, Biblioteca do Mristéio da Fazenda; Centro de Doamentação da Escola de EnfermagemAnna Nery - UFR; Centro de Pesquisa e Doamentação de Histónia Contemporânea do Brasil da Fundação Cetúlio Vargas; e Biblioteca do Centro de Estudos do Hospital Pirnel.

As fontes seandárias forama literatura pertinente à Histónia do Brasil, especificamente o Estado Novo; à política de saúde, com destaque para a Reforma Capanema; à História da Medicina, emespecial a constituição e consolidação do campo psiquáticico no
Brasil; à Hstónia da ErfermagemBrasileira, priorizando particularmente a trajetória da EPEI e seus nexos coma EAN Para subsidiar a artialação das fontes ao contexto, foi elaborado um esquerra de análise diacrônica e sincrônica de fatos e eventos pertinentes ao objeto emestudo. A análise da estrutura dos campos e dos respectivos sistemas de relações permitiu esdarecer as circunstândias em que ocorreramas mudanças de numb emu moleterminado momento da histónia da $\mathrm{PPE}$

\section{OS CAMPOS DA PSIQUIATRIA E DA SAÚDE PÚBLICA NA PRIMEIRA REPÚBLICA E A FORMAÇÃO DOS (AS) ENFERMEIROS (AS)}

Nbfinal doséaloXX raE Eropa, a psiquiariaconstitiu sues beses conto campo de saber especializadb ${ }^{1: 115}$. No Brasil, a consolidação desse campo se deu no alvorecer da Primera Pepública, a partir da nuptura da aliança entre a comporação médica alienista e a Igreja Católica, que alminau coma retirada das imãs de cricadedo do hospácio da Praia Vertelha:438.

Esta espedialidade continuou a fundamentar suas práticas, suas posições e as relações entre seus agentes no roddo asilar2:43, oriundb da França e aqui reprod ridb pelos agentes alienistas brasileiros ${ }^{3: 15}$. Pautada no tratamento mord e na ordenação do espaço institurional, esta pedagogia da disciplina subsidiou as ações terapêticas e de ensino mo espaço do hospácio.

Nâo dbstante, no século XX a melhor estratégia dos alienistas foi a de conferir à loucura uma especificidade, ao concebêla como uma doença, transformando-a emobjeto de corhedimento exdusivo do rédico. O termo preferido pelos rédicos para designar o louco foi o de alienado; assim os agentes nédicos que atuavamna área passarama se denominar alieristas, coma competênda de dscermir e julgar tudo sobre a alienação nerta, à luz do saber psiquátrica. Nb entanto, a necessicade de expandr o campo da psiquidria demandou diversas estratégias, desde a substituição de crenças e valores do senso comm por prinápios dentúficos, nes reformas legais relatives à assistênia aos alienados ${ }^{4: 5}$, até a extensão da autoridade do alierista, sobre o maior núnero possíed de indvídus, semdstinção de gênero, cơ e posição social:118.

Tal projeto exigiu que os agentes alienistas, em vários momentos, se aliassemou se confrontassem comautros rédicos e tambémcomagentes de outros campos. Assim eles formaramalianças comagentes dos campos concorrentes (médico-legistas, advogados, juízes) e se colocaramno papel de 
defensores e protetores exdusivos dos alienados, contra as pessoas que os rodeavam desde amigos e familiares até corretores de negócios, rábulas (advogados leigos), notários públicos, fâmulos (criados), enfermeiros e até médicos ${ }^{1: 13448}$

Nb bojo desse processo de consththição e consolidação do campo da psiquiatria no Brasil, ocorreu em1890, a criação da Escola Profissional de Enfermeros e Erfermeriras no Hospácio Nacional de Alienados (HN).

A Escola Profissional de Enfermeros e Enfermeras logo recebeu cúticas dos alienistas, por não a mprir a exigênia legal de que preparasse profissionais para os hospitais emgerd. Os empealhos a tal desiderato eram a insuficiente organização adhinistrativa da Escola ea sua depeendência do Hospácio Nacional de Alienadbs6:201.

A contrário, a partir de 1911, have a expansão dos hospitais psiquiáticos sob a forma de colônias especúficas para cada sexo. O rodklo de tratamento, adbtadb de forma progressista, era o organicista (somático) e psicológico de arho preventivo, segundo os preceitos ca higiene mental, emsubstituição ao tratamento moral, o que demandaria a formação de profissionais mais espedializados ${ }^{7: 21}$. Nestesertido, em1916, pesquisadores da Fundação Rockefeller (FR) registrarama falta de enfermeiras diplomadas brasileiras:131.

Após a 1a Grande Grera, em1920, o rédico bra sileiro Adblpho Possollo, passou a defender a criação de umarso regular de enfermagem que oferecesse noções sobre o organismo humano e a assistênda nas especialidades médico-cinúrgicas. Por mais de una vez, Adblpho Possollo expressou sua expectativa de que a nova seção da $\mathrm{PP}$, na Colônia Ferinina do Engenho de Dentro, viesse a satisfazer essa necessidade e aspiração da dasse nédica brasileira: ${ }^{9} \mathrm{MIX}$. Seu discurso atribuía à enfermeira as qualidades devocionais, como o espínito de sacifício, a dedica ção, a reiguice e a espontaneidade, tidas como inerentes à condção feminina Tal visão reforçaria $a$ dbminação masaulina dos agertes nédicos sobre o gut po de enfermeras, segundo uma divisão aparentemente nomal e natural. Tal divisão se faz presente emtodo mundo social, objetivado nas coisas e incorporadb nos agentes, emseus corpos e no seu habitus, funcionando como esquentas de percepção, de pensamento e de ação' ${ }^{10: 17}$.

Ainda nos anos de 1920, já no contexto da Reforma Sanitária Carlos Chagas, atuou no Departamento Nacional de Saúde Pública (DNSP), na cidade do Rio de Janeiro, a Mssão de Cooperação Técrica para o Desenvolvimento da Enfermagemno Brasil, sob os auspácios da Fundação Rodkefeller ${ }^{11: 16}$.
A dhefe da Mssão, Ethel Parsons, registrou emseu relatónio inicial a superlotação dos hospitais do Rio de Janeiro, onde a enfermagemera exercida por pessoas ignorantes, de ambos os sexos, e em condições precárias. Apesar de julgar os médicos interessados, para ela, o entendimento deles era o de que o Brasil não poderia ter enfermeiras qualificadas cono aquelas que eles haviam conhecido no exterior:68. Ao mestro tempo foramtomadas medidas cautelares, no sentido de garantir a posição da EPEE no campo da enfernagem Assim no dia anterior ao da chegada de Ethel Parsons ao Rio de Janeiro, dezesseis anos após a reinauguração da EPEE, foi publicado um novo regimento interno ${ }^{12}$ dessa Escola, assinado pelo ministro da Justiça e Negócios Interiores Afredb Pinto, dais dias antes de sua sáda do cargo.

OCongresso Nacional dos Práticos (AP), inserido nas comemorações do centenário da independêndia do país (1922), evidenciou os conflitos entre os diversos agentes no campo médico. Apesar de outras discordândias, o evento uniu a conporação contra todos os demais agentes na área da saúde, de modo a ampliar e consolidar a hegentoria do nédico, nos mais veriados aspectos da vida social. Os interesses dos agentes nédicos presentes no QN (generalistas e espedialistas), e representados por suas lideranças, se deramem três aspectos: o donínio das áreas do saber médico; o nonopólio do mercado de trabalho; e a formalização de nomas de condita Neste campo de lutes, a conporação rédica, pauco honogênea, coerente e hamôrica, debateu sua autonomia e es posições relatives de cada grupo, indusive indicando a posição e situação de outros agentes, concorrentes ao rédico ${ }^{13: 30-37}$.

Neste Congresso, Ethel Parsons, emseu trabalho sobre "As enfermeras de saúde pública", apresentou a enfermera de saúde pública como una reformadora social, ajas funções seriamas de aidar dos doentes, proteger os sãos e ensinar os prinápios de higiene individual. A relatora esdareceu que o arso de enfermeiras do DNSP não interferina na prática nédica, ajas ativiclades mais nobres não estariamao alcance das enfermeiras. Parsons tambémelogiou a dara visão de Carlos Chagas e valonizou os nétodos de educação do higienista e jomalista José Pararhos Fontenelle $\mathrm{e}^{3: 74}$. As consideraçōes de Pierre Bourdieu, de que as antigas estruturas da divisão do trabalho determinarama direção e a forma das mudanças que seriam objeivivadas nos níveis, nas carreiras e nos cargos, fortemente sexuados, se aplicamao texto de Parsons, emseus três prinápios: primeiro - as funções que convêmàs milheres se situavammo prolongamerto das fun- 
ções donésticas; segundo - una milher não pode ter atoridade sobre hom trs; se vier a eercer funçôes iguais, ver-seá preterida por umhonempara posição de autoridade, terceiro - o homentemo monopólio da manur tenção dos djjetos técricos ${ }^{10.112}$. O disarso de Parsons atingiu vários objetivos: a aceitação, pelas lideranças nédicas, da Escola de Erfermerras do DNSP, a gerantia do ronopólio dos senviços de enfermagemàs futuras efermerras e a ampliação do seu mercadb de trabalho. Cabe ressaltar que no OP tais questões estavemdireta mente ligadas à disassão e ao debate da autonomia na prática nédica e à heteronomia dos autros profissionais no campo rédico.

A proposta de Parsons dividiu os congressistas: os higienistas/sanitaristas, liderados por Carlos Chagas, a enalteceram chegando a propor que o AP se nanifestasse perante as autoridades competentes, apontando a necessidade de seremcriadas diversas escolas de enfermeras no país; umsegundo grupo, aja posição foi defendida pelos psiquiatras Julio Peres Portocarrero, Inineu Pontes Malagueta e José Borifácio Costa, defendeu os interesses dos médicos, alertandoos de que o incremento da formação dos enfemeiros seria uma areaça ao seu monopólio no campo, ressaltando que o regulamento do DNSP não garantia a submissão da enfermeira ao nédico ${ }^{13: 78}$. Ao apoiar a proposta de formação de enfermeiras de alto padrão, os sanitaristas colocavamse emoposição aos psiquiatras, viltadbs para o modlo francês, do fimdb séar lo XX aja imagemideal da enfermeira era aquela devotada à República, à Assistência Pública e aos seus representantes, os médicos ${ }^{14: 6}$. Assimos psiquiatras brasileiros temiamque as enfermeras invadissemo terreno da prática médica. Por isto, os psiquiatras insistiamemque as enfermeiras tivessemlimitadas suas funções, recebendo tambémumensino 'sacerdbtal $^{13}$, ao contránio do habitus profissional defendido por Parsons, mais técico e voltado para a eficiênia.

Esta relação assimétrica entre o psiquiatrahomem e a enfermera-milher encontrase bemrepresentada na Figura 1, que corresponde a umquadro de formatura da Escola Profissional de Enfermeras Alfredo Pinto. A ilustração apresenta como símbolo de prestígio três fotos de professores formando umtriângulo invertido. No centro do triângulo, o título do conjunto: 'Diplomadas de 1923'; à esquerda, como homenagea do, o psiquiatra Emani Lopes; ao centro, de beca e capela, o paraninfo Zópiro Gulart (higienista mental, dínico, jomalista e poeta); à direita, o diretor da Escola, o psiquiatra Gistavo Riedl; e no centro, ladeando a foto do paraninfo e tambémabaixo desta, estão as fotos individuais das formandas: nove milheres com uniforme de enfermeiras portando toucas no estilo francês, comuma cuz no centro. Merece destaque ainda a formanda negra e sua significativa inserção na parte mais baixa do conjunto. Na base do quadro, encontramse os dizeres Escola Profissional de Enfermeiras Afrredo Pinto', denoninação dada à Seção Escolar Feninina, recorhecica na Colônia Ferinina do Engerho de Dentro, a partir do Regimento de 1921 Cabe desta car, ra simbologia da Escola, a presença da cuz no inte nior de umáralo e nes toucas das formandas, no entan to, o símbolo naior da enfermagemmodema, a lâmpa da de Horence Nghtingale, está auserte.

Figura 1: $Q$ uadro de formatura da turma da Seção Feminina da EPEE, em 1923.

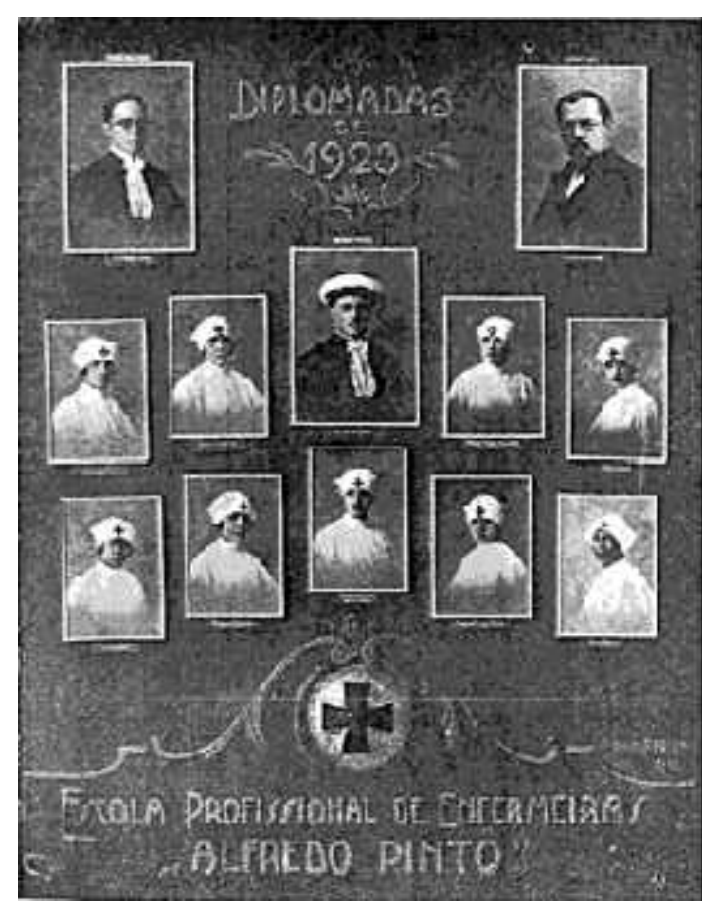

Fonte:Anais daColônia GustavoRiedd, 1944, p. 309 (fac símile). ArquivoSetorial daEscola deEnfermagemAlfredo Pinto/Laphe/UNRO.

Nbs anos de 1920, o Brasil vivia o impado do movimento revolucionánio dos "tenentes" que, em1930, ajudaria Cetúlio Vargas a dembar o poder digárquico da Pinera República A ascensão de cetúlio contou como apaio da lgreja católica, que garantiu a adesão de enomes contingentes populacionais emtroca de medidas a seu favor, dentre elas a implantação do ensino religioso nas escolas públicas ${ }^{15: 185-94}$. A reaproximação entre Estado e Igreja, desfeita pela Primera República, provocaria resultados práticos no campo da saúde, como o amparo legal às Imãas de Caridade, que vinham praticando a enfermagemnos hospitais, que tiveramgarantido dreitos iguais aos das enfermeras diplomadas ${ }^{16: 244}$. 
O NOVO MINISTÉRIO DA EDUCAÇÃO E SAÚDE PÚBLICA

Na visão centralizadora do Covemo Provisónio de Ce túlio Vargas, fai criadb o Mristério dos Negócios da Edtr cação e Saúde Púdica (MESP) ${ }^{17}$. A Aciação de umúrico ministéio para a educação e a saúde pública acabaria determinando una hierarquização no interior desse espaço de poder, pais, mo interior de cada campo, os agentes lutampelo monopólio do poder ou para impor e manter o predońnio da forma particular de poder que dêên ${ }^{8}$. A posição mais atta nesta estutura fai œapa da por umporta-voz dos educadores, o que garantiu a estes mais poder e distinção do que aos nédicos.

OMESP nostrau a disposição do govemo emintenir e nomatizar os campos da educação e saúde pública emtodas as regiões do país, bemcomo as práticas profissionais inseridas neste campo. Desse modo, o caráter téorico-legislativo do MESP o colocava corro um espaço de intensa luta política, tanto no entbate entre os campos da ed cação e saúde, cono pelas especificidades e especialidades inerentes à área da saúde

A estruturação e a organização do campo da edtr cação e saúde ocorrerama partir de decretos do govemo provisónio:19:134. O decreto 19560/1930, que fixou as atribuições do MESP, reflete a visão centralizadora do govemo, que a ele atribuía o estur do e o despacho de todos os assuntos da adhinistra ção federal, relacionados como desenvolvimento intelectual e mord; a defesa médico-sanitária da cole tividade social brasileira; e a finalidade legislativa para a educação e a saúde Na prática, o novo ministério pessou a controlar todos os atos a seremreferendados pelo dhefe do poder exeativo.

Nb entanto, o confronto de forças políticas acabaria remodelando a estrutura inicial do ministério, de acordo coma conveniêndia dos diversos grupos concorrentes. O resultado deste embate deu aos intelectuais educadores a liderança do novo Mnistéio, no espaço do Departamento Nacional de Educação. Quando o DNSP foi integrado ao MESP, já tima una estrutura apoiada pela Fundação Rodkefeller e uma histónia no campo da saúde pública, o que garantiu aos sanitaristas força suficiente para liderar e influenciar as reformiações afetas à saúde.

O Departamento Nacional de Assistênda Pública (DNAP) teve sob sua responsabilidade a Inspetoria Ceral dos Hospitais, a Assistênaia a Psicopatas e seus respectivos estabdlecimertos. Nb entanto, nove reses após, o decreto 20563/1931 reposicionou a Assistênaia Pública emuma diretoria subordinada ao DNSP. OS sanitaristas davamassimuma demronstração de força, ao contránio dos psiquiatras, que perderam posições na estrutura hierárquica da saúde.

Na restra época, foramproduvidos decretos para a regulanetação do exerácio de vénias profissões de saút de, abrangendb a enfermagem a farmácia e a odontologia comvistes ao desennolvimento dos seniços a cargo da Comissão Rockefeller e ao atendimento hospitalar ${ }^{20}$.

Ampliourse tanbémo contrato coma Fundação Rockefeller, para a exeaução de medidas profiláticas contra a febre amarela, emtodo teritónio nacional. Apesar da mudança na ordeminstitudional do Brasil, no governo provisónio de Varges, a saúde pública nadonal se manteve sob a influênaia norteameicana, ca racterística que marcara a saúde pública na segunda metade da primera República Enquanto isso, os sanitaristas do DNSP tratavam de garhar visibilidade, atribuindo as reduçães nas taxas de mortalidade, ocomidas descle o início da República, ao resuttadb das ações de saúde púdicaro. Ao destacaremsues açoes, os saritaristas pleiteanammaior solicitude do poder público, em prol do desenvolvimerto da orgarização sanitária. Are forma proposta por des resultaria emu ma methor distribuição das açães sanitánias entre os diversos órgãos exe ativos nes diversas unidades da Federação, coma cia ção de centros de saúde, de hospitais, sanatónios e preventónios contra a tuberalose e a lepra, bemcono a ampliação das ações de higiene infantipo.

Para os psiquiatras, sua transferência do campo da justiça para o da educação e saúde colocava emrisco seus poderes na estrutura do aparelho de Estado. Os psiquiatras reagirambuscando demonstrar a necessidade de romper coma assistênda pautada no modlo institurional fechado, como evidendiava a superlotação do HNA Ees alegaramque este regime tirava do interno a capacidade de govemar sua pessoa e seus bens. Esse argumento fundamentou u ma de suas révindicaçães: a revisão da situação juńdico-social dos internos e a definição, por meio de ato legislativo, da personalidade juńdica dos psicopatas e de sua capaddade óvil, de acordo comsua aptidão mental. Os novos rétodos terapêuticos e de hospitalização deveriamter, portanto, umenfoque preventivo e meredia a uilização dos rearsos educadionais, conforme os ide ais de Gstavo Riedd ${ }^{21: 288}$.

Onovo rodlo assistendal visava a redurir em $30 \%$ o número de crônicos internados e indúa os seguintes senviços e atividades: 1) rastreio de "pequenos psicopatas", profilaxia, anbulatónio, dispensário e educa ção; 2) Instituto de Pesquisas Psicológicas, orientação e seleção de profissionais; 3) senviço aberto, para 
hospitalização dos psicopatas agudos; 4) seniço fe chadb, para psicopatas crônicos, emcondições de partiapar da praxiterapia; 5) senviço de assistência heterofamiliar, no qual as enfermeiras e seus familia res residiamempavilhões tipo bangalô, coma doriga ção de aidar de dues pacientes emcondiçães de conviver emfamília de nodb a pronover sua readaptação social; 6) Escola de Enfermeras, para cuidar das insanas ou exercer a função de visitadoras sociais, educadoras do povo; 7) praxiterapia: oficinas de costura, renda e bordado, cinema-teatro, jardinagem hortialtura, pomialtura e apialtura ${ }^{21: 288}$.

$\mathrm{Nb}$ que se refere ao compo da psiquiatria, as prinipais autoridades da Dretoria de Assistêndia a Psicopatas proararamremover os doentes mentais para a zona nura do Distrito Federal. A Cô̂ria Gustavo Riedl no Engerho de Dentro destacarse cono lugar onde eram aplicados commais efetividade os prinápios da higiene nertal, por nié das atividades de prevenção e profilaxia dos distúrbios metais, emnivel anbulatorial. Alémdsso, dela fazia parte a seção ferinina da $\mathrm{P}$ EF, que possibilitava às erfermeriras formadas acrescentar à sua fornação umarso de visitadbras sociais.

As providênaias previamainda a melhoria das instalações da $\mathrm{PPE}$, coma reforma da sede da seção feminina, bemcomo a ampliação das colônias de Jacarepaguá e do Engerho de Dentro, para que estas unidades pudessem receber os doentes renovidos do HNA a ser desativedo. Enquento o projedo dos psiquiatras limitava sua abrangênda ao Distrito Federd, preconizando a mudança do modelo assistencial e a melhoria das instalaçoes, a política geral do MESP impulsionava seus órgãos para ações de amplitude racional. Oplano destes agentes, a partir de 1934, foi o dedefirir a situação juńdicosocial dos pacientes, ampliar os espaços dos psiquiatras nas instituições e implementar o modlo profilático, por meio de medidas legislativas. O novo modelo da assistência psiquátrica, legalizada pelo decreto 24559/ 1934, atendeu a algumas das reivindicações dos psiquiatras e favoreceu noves alianças e estratégias de proteção do campo psiquiátrico contra possíveis intenenç̃es de outras áreess da saúde

A primera estratégia foi a criação do Conselho de Proteção aos Psicopatas, presidido pelo ministro da Educação e Saúde Púdica, tendo cono vicepresidente o diretor geral da Assistênda a Psicopatas, e constituídb por representantes do campo e de sues alianças. Suas atribuições eramas de aconselhar o governo sobre a proteção aos psicopatas, além da cooperação com organizações públicas e particulares de fins humarísticos. A extensão desse conceito aos estados resultau na criação de Comissões Inspetoras. Ocampo da psiquiatria ampliava assimo seu poder no aparelho de Estado, por meio, não só da indusão de novas atribuições, mas do controle exdusivo dos órgãos da Assistêndia a Psicopatas, nos níveis central e local.

A segunda estratégia foi a ampliação do conceito de estabeledimento psiquátrico, que pessava a induir, além dos que se destinavamà hospitalização de doentes mentais, as seções especiais de hospitais gerais, bemcomo estabelecimentos de assistênda social, de várias naturezas. Além de ampliar substancialmente o campo psiquátrico, essa estratéga, ao fixar que a dreção desses estabdleaimentos caberia a profissionais habilitados, tambémamplicu o mercado de trabalho para os psiquiatras. Ser habilitado era possuir umcapital espedializado empsiquiatria como professor de dínica psiquaátrica nas Faculdades de Medina ou ter, pelo menos, dois anos de exerćác eetivo como psiquiatra ou assistente, emseniços psiquátricos.

A terceira estratégia foi a da incorporação dos toxicômanos e dos intoxicados habituais ao grupo dos psicopatas, já medicalizados e dassificados pelo ideénio da profilaxia, da higiene e da eugeria Assim todos os que predisassemde uma instituição psiquátrica aberta ou fechada, ainda que momentaneamente, passaram a ser responsabilidade dos psiquiatras.

OS DESDOBRAMENTOS NA FORMAÇÃO PROFISSIONAL DE ENFERMAGEM NAS ESCOLAS PROFISSIONAL DE ENFERMEIROS E ENFERMEIRAS E ANNA NERY

Entre a segunda e a terceira décadas do séalo XX, pessarama coexistir, na capital federd, duss visões concorrentes de escola de enfermagem Tais visões reflejama luta de agentes nédicos que turavamemcampos espećficos (saúde pública e psiquiatria), que œa pavam posições dfferentes no aparelho de Estadb e que, apesar de seremportadores de alguns interesses antagônicos, tinhamcono interesse commo exerácio do poder sim bólico sobre os agentes de enfermagem

Ogoverno provisónio, ao regulamentar o exerácio da enfermagem pelo decreto 20109/1931, estabele ceu a Escola Arna Nery como "escola-padrão" para efeito de reconhecimento das demais escolas 22:88. A afimativa contica neste decreto: "Urge, pois, fixar o padrão de ensino de enfermagem.". sugere a existência de padrões concorrentes de ensino na enfermagembrasileira Entre os requisitos básicos para a equiparação de uma escola à Escola Arna Nery, estava a exigência de que sua dreção fosse exercida por erfer- 
meira diplomada, comaurso de aperfeiçoamento e experiênia de ensino e administração de escolas. Nbs considerandos do decreto, comentourse a possibilidade de anexar a EAN à Universidade do Rio de Janeiro, futura Universidade do Brasil, o que não ocorreu em virtude de "converiêndas da organização sanitária". Assim o modelo da EAN levou as enfermeiras diplomadas a conquistar espaços no aparelho de EStado do governo Vargas, e até despertou redanações dos agentes nédicos $23: 134$.

Mbças de boa formação e família eram as candidatas adequadas a uma profissão jovem coma pretensão de conquistar e oapar lugares de destaque na sociedade Quando a enfermagemmodema foi implantada, portanto, a figura masalina foi exdúda desse movimento, pois rapazes de boa formação e família eramherdeiros das profissões hegemônicas, que já haviam conquistado espaços privilegiados no mundo social. A presença do enfermeiro, até restro emuma modalidade assistendial como a psiquiatria, na qual os agentes de enfermagemdo sexo masalino oupavamespaço importante, não era bemvista pelo grupo das enfermeras diplomadas, provavelmente receosas de que tal aproximação pudesse prejudicá las na hierarquia do campo.

Nấo tendo ocomidb a reorganização administrativa e pedagógica da Escola Profissional de Enfermeiros segundb o padrão Arna Nery, passarama coexistir no Mnistéio da Educação e Saúde (MES) dbis rodelos de formação de enfermeros(as): 1) o rodlo da Escola Profissional de Enfermeiros e Enfermeiras da Assistência a Psicopatas do Distrito Federal, com seções "mista" e feminina; e 2) o modelo angloamericano de enfermagem moderna, elevado à condição de padrão oficial, que oferedia o arso geral de enfermageme que representava uma ameaça à hierarquia vigente no campo psiquiátrico.

Ao contránio do que ocomia no DNSP, onde se dosenvava a participação das enfermeriras diplomadas em posições estratégicas, não se constatou participação de agentes enfermeiros(as) da EPE, na Diretoria de Assistêndia a Psicopatas (DAP), o que não era djjetivo dos psiquiatras. Dá porque as qualidades necessárias aos enfermeros(as) de insanos, ressaltadas durante toda a década de 1930, pelos representantes do campo psiquiátrico, não indúamaspectos relativos à liderança e à organização de senviços, optandb eles por qualicades que mantivessemos agentes enfermeros emcondição de sulumissão aos psiquiatras.

Enbora os antigos requisitos para o ingresso na PEE continuasseminalterados, a opinião dos psiqui- atras passou a ser mais favorável à seção escolar fe minina do Engenho de Dentro do que à seção mista do Hospital Psiquiátrico da Praia Vermelha, indusive por questões de gênero, coma exaltação das caracteństicas sociais femininas para a assistência de enfermagemaos psicopatas, já que o novo modelo de assistênaia não enfatizava o uso da força musalar para a contenção do doerte menta. Alémdsso, os prinápios de profilaxia da dbença mental vimamsendo desenvolvidos na Colônia Feninina Esta atividade tinha cono lous de intenvenção os lares, espaço donéstico resenva do às milheres na divisão do trabalho sexul e social. Comb expressou o renonado psiquiatra Plírio Cinto ${ }^{24: 16 .}$

Na prática domialiar, a enfermeira se transforma emmoritora Visitando seu dbente ou a família dele, a monitoria será menos expansiva, mais discreta, mais severa Tomandb sues notas para a ficha familiar, obsenva o meio emque vive o doente e verifica đá que ponto a conviênda lhe será favorável ou prejudidal (...).

Com essas responsabilidades [consciênaia, lealcade, dbediênaia, ponturalidade, autodonínio, baixo tomde vaz, cooperdiva e aidadosa] cresce de importânia o exerácio de una profissão que no momento atul é talvez a mais nobre que se possa entregar nas nãos de una miher.

As questões de gênero provavelmente se assemelhavamnos espaços da Escola Ama Nery e da Seção Feminina da Escola Profissiona, prinapalmente no que se refere ao papel das enfermeiras e sua identificação com a posição feminina no espaço doméstico, como se vê no discurso autorizado da diretora da EAN Radhel Hbddbdk Ldbo ${ }^{25: 06:}$

A enfermeira moderna é nãe desvelada, noite e dia à cabeceira dos que lhe foramconfiados na ausêndia do médico, que tranqülo pode entregar-se aos seus afazeres... é a educadora dos lares, a aperféçoadora da raça (...).

As enfermeiras, no entanto, possivelmente não tinhamcomo avaliar sua situação pois, quando os pensamentos e percepções estão estruturados de conformidade comas relações de doninação impostas, os atos dos dominantes passama ser reconhedidos como naturais. Por não leverememconta os efeitos duradouros da ordemmasculina, as mulheres não poderiamcompreender adequadamente a submissão em que se encontravam o que constitui o efeito caraderéstico da violênaia simbólica' ${ }^{10: 22 ; 53}$.

Os representantes do campo psiquiátrico reproduziame atualizavam seu discurso sobre as 
"qualidades necessárias a um enfermeiro de psychopatas", descritas em1933 por Juliano Mbreira²6, baseado no pensamento do alierista belga Julio Mbrel. Tais qualidades foramagnupadas em duas vertentes de submissão e subsenviência. A primeira delas considerava o médico o dhefe absoluto emrelação à arte de aidar dos pacientes; a segunda visava presenvar a instituçãa, induzindb a enfermera a jamais falar dos acidentes dentro ou fora do estabdedimento, dos óbitos, das evesões, das tentatives de suiádio.

Ainda comrelação aos requisitos básicos exigidos, Juliano Moreira alinha mais de quarenta qualidades desejáveis para a enfermeira, entre as quais boa nemória, exatidão, prontidão de espínto, doģura, capaddade de obsenvação, previdência, paciência ilimitada, "sangue frio" e domínio absoluto de si mesma. Náo obstante tantas qualidades, a enfermeira não tima reconhedida sua capadidade de decisão, nemmesmo emrelação ao dbjeto de seus aidados, una vez que, quando rão lhe fosse possivel fazer a vontade do doente, deveria desaipar-se, invocandb o regulamento do hospital, ao qual tima que se submeter.

Ao contránio da EAN a PPE enfrentava officuldades quanto ao recutamento de candidatas como o perfil de moças de boa família Aémdo preconceito que cercava o trabalho de enfermagem em geral, a situação era mais grave no que se referia à assistênda a psicopatas, já que este aiidado, prestado em instituiçoes fedhadas, envolvia o contato compacientes sem censura e sujeitos a episódios de violência explídita. O contexto que envolvia o preparo do profissional, formadb emescolas dirigidas por nédicospsiquiatras e às vezes em dasses mistas (sem separação por sexos), tanbém era visto com desconfiança pela sociedade. Esta diferença é evidenciada na dedaração de Juliano Mbreira26:85, ao frisar que emalguns páses mais adiantados, já havia moças educadas e interessadas em trabalhar na assistência aos alienados:

... Por toda parte do mundo divilizado, os effermeros têmadquirido uma alta reputação e são mito considerados. Na Hdanda, na Ingatera, na Alemarha, e nos Estados Unidos, já hoje pessoas pertencentes às dasses superiores da sociedade não se desdairammais emalistar-se entre as enfermeras de hospitais de alienados.

Os problemas que desafiavamos psiquiatras da EPEE eramvários e de caráter contraditónio: se, por umlado, eles proaravamevitar que os profissionais de enfermagemameaçassemsuas posições, por autro tentavam superar os preconceitos relativos à assistênia de enfermagemaos doentes mentais, de modo a conseguir recutar candidatos como capital altural necessário a ummodllo de formação capaz de equiparar a $\mathrm{IPE}$ à escolapadrão ${ }^{27}$.

Iniciativas desenvolvidas à época acabariampromovendo una certa aproximação entre as instituições. Asuperintendente do Senviço de Erfermagemdo DNSP, Edith Fraenke, levou ao corhedimento de Bertha Pullen a visita que os professores da $\mathrm{BEE}$ friamà sede da EAN em1935"2. Oepisódio indica que a superintendente atuava como mediadora entre o grupo de professores psiquiatras da EPEI e a EAN comandada por enfermeras diplomadas.

\section{CONCLUSÕES}

No períodb estudado, o campo da educação e saúr de, e nele os da saúde pública, da psiquiatria e da enfermagem estruturourse a partir dos prinápios de visão e de óvisão, que orientaramas lutas, as controvérsias e as competições entre os diversos agentes envolvidos e impuseramos limites históricos ao de senvolvimento de cada qual, emseu interior.

O argumento comque os psiquiatras defenderam o seu projeto para a $\triangle P E E$ era o de que o corhedmento a ser incorporado pelos enfermeiros(as) deveria pautar-se pelas espedialidades rédicas, emdetrimento de umconhedimento mais espećfico de enfermagem de modo a inculcar, na formação do enfermeiro(a), o reconhecimento à supremacia do médico e a dedicação à sua pessoa.

A Escola Profissional de Enfermeros e Enfermeiras manteve-se como objeto de dominação simbólica dos rédicos psiquiatras. Estes, ao lograremprodurir umdisarso comefeitos de verdade, puderamoperar a naturalização do seu poder naquele espaço social e, portanto, o reconhecimento da legitimidade de sua presença No entanto, décadas de poder dos psiquia tras na direção e no ensino da Escola não resultaram na formação de um agente de enfermagem que complementasse de fato a atuação do psiquiatra.

A Escola Arna Nery, liderada por enfermeras ame ricanes e inserida no campo da saúde pública, garantiur se cono ummodlo de escola-padrão, assumindb sua possibilidade histónica de resguardar o poder e a aut tonomia das enfermeras diplomadas, contra o mode lo concorrente baseado na dominação dos psiquiatras, que conseguiamno seu campo impor a verdade sobre a formação de enfermeiros e enfermeiras. 


\section{Referências}

1. Engel MG Os delííos darazão: nédicos, laucose hospíios-Rio dejaneiro 1830-1930. RiodeJaneiro(B):: FORLZ; 2001.

2. Madhadb R La reiroA LuzR MricyK Daneçãodanama:medaina

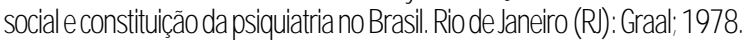

3. AmudaE Resuntristórico dapsiquiatriabrasilera Riodejaneiro (B)): URP; 1995.

4. Desctor 151559, de7deatubrode1893. Dspõesdrearearorizacão

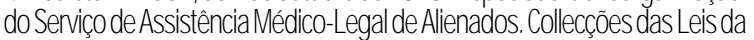
ReáblicadosEstados UhidbsdbBrazil. Atos db Poder Exeativo. Riode Janeir(LF): Impressankajind; 1894. p689-771 v.1e2

5. Decreto $n^{\circ} 8.834$, de 11 dejurho de 1911 . Dispõe sobrea reorganizacããodazssistência aosalienados. Collecções das Leis da Repudicados Estados Uhidos do Brazil. Atos do Poder Exeativo. Riodelaneiro(DF): Impressa Nacional; 1915. p.139-68. v.2. (Mbdificauadenominaçãodelbspácio Nbaional deAlienados para Hospital Nacional deAlieredos)

6. Pontes C Contribuiç̃oàhistóniada enfermagen+EscoladeEterermagemAlfredb Pinto: a pioneira das escolas de enfermagemno Brasil. RevBrasEferm1971 abr/jun; 24(3/4): 199-214.

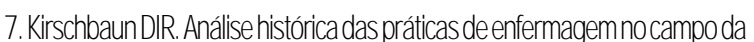
assistêniapsiquáticanoBrabil:perícobconpreendobetreasdécadbsce 20 50.Pevldino-AnEtermagen1997maia:5(n esp): 19-30.

8. Sauthier], Barreira, IAAserfermerasnorteamericaneseoensin daerfermagennacapita doBrasil: 1921-1931. Riodejanero(B)): URJ/ EAN 1999.

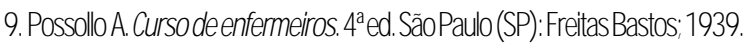

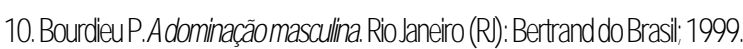

11. BarreiralA Os primúrdios che erfermagemmodemanoBrasil. EscArnaNeryRevErferm1997ju; 1 (n lanç): 161-76.

12. MristériodaJustiçaeN Negócios Interiores(BR). Portariade1ㅇde setentbrode1921. Aprovao regimentointernodaEscolaProfissioral deE fermerrose E fermeriresdaAssistêniaaAlienedbsdoDistitoFederal. Dário Cficial da República Federativado Brasil. Riode Janeiro(DF), 01 set 1921: Seção 1.

13. PereiraNktoAF.Ser médicono Brasil:opresentenopessadb. Rio dejaneiro(B): HORLZ; 2001

14. Slvajurior $\propto$, BragaMN AEscola Profissional deE Efemerirose Efermeriras do Hosácio Nacional dos Alienados ea enfermagermo alvorecer doséalo XX 1890-1921. Riojaneiro(R): UFP); 2002. (Relatóniofinal depesquisa)

15. FaustoB. HstóniadbBrasil. SãoPaulo(\$): EdUథ; 2000.

16. BezerraMRM BaptistaSS AcriaçãodaEscoladeE fermeriras LuzadeMrilac estratégias paraamantencão do poder caigreja católicanos espaços hospitalares. EscAmnaNeryRevEffermz002 ago; 6(2): 241-53.

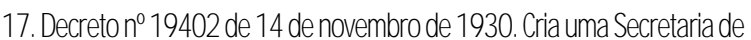
EstadbcomadanomiraçãodelMristéiodbs NegódiosdaEdraçãoeSáde Púdica Rodejaniro(DF); 1930. (ClecãodelésdbBrail).

18. BardeuP. Opoder sinbólico. Lisboa(PO): Dl田; 1989.

19. HodmanGAsándepíblicaenternosdeCapanen a cortinuidades

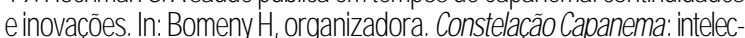
tuaisepditicos. Riodejaniro(B): FG/,2001.
20.MristériodaEducaçãoeSaúdePúdica(BR). Pelatóniodagestão doMnistro WtashingtonFerreiraPires: 1932-1934. Riodejaneiro (DF): Impressanadional; 1934. 128p (AcervodaCasadeOswaldo (nzz- Menguinhos, Pl).

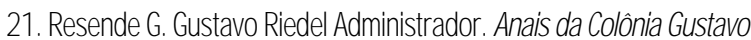
Riedl 1943; 6(6): 287- 89.

22. BaptistaSS Trajetóniadas escolas deerfermagemmasociedade brasileira. EscAmaNkryPevEnferm1997dez; 1(2): 85-105.

23. BarreralA Contribuições daH HtóniadaErfermagemBrasileira para o desenvolvimeto da profissão. EscAmaNery RevEnferm 1999 dor, 3(1): 125-41

24. OintoP. Aptidões edeveres daenfermera de hygienemental. Anais Efferm1932 maio; 1(2): 16-17.

25. LoboRH Eranova. Anais Efferm1932maio; 1(1).

26. Moreira J. Qualidades necessárias a umenfermeiro de psychopatas. Arquinos Brasileiros deHygieneMventa 1933abr/jun; 6(2): 78-86.

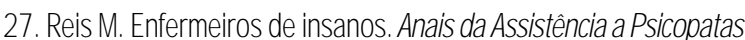
1941;131-40.

28. UhiversidadeFederd doRiodejaneiro. EscoladeErfemagemArna Nery. CertrodeDoa mertacão. Comespondêndiadeagostode1935.

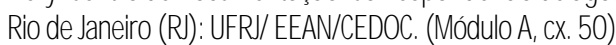

\section{Nota}

TrabalhogarhadbrdoPrênio 2ొColóquioLatino-AnericanodeHstóia deEfermagem- Rio, 2005.

\section{Sobre os Autores}

\section{W: iglon MendorsadeAnoin}

Professor Aduntodb DepartamentodeE EfermagemdeSádePúdica da Escola de EnfermagemAfredo Pinto, da UNRIO, Mentbro Fundador do Laboratớiode PesquisadeHstóniadeE Eferragem/ Laphe; Mentbro Fundador do Núdeo de Pesquisa de Hstónia da EffermagemBrasilera/Nuphebras/EAN/URI.

E-mail:amorimn@i.combr

\section{ledade/Aencar Bartéa}

MentbroFundador do NúdeodePesquisadeHstóniada Enfermat gemBrasileira- Nuphebras. Pesquisadora 1Ado CNPq. Ĺder do gupodepesquisa"Apráticaprofissiond eaformaçãodaidanticade daeffermerabrasileira". Exprofessoratitular db Departamentode Erfermagemfundanenta/ 